\title{
2013 Scientific Achievement Award recipient: Eugene H. Blackstone, MD
}

\author{
Joseph F. Sabik III, MD
}

\author{
"We are what we repeatedly do. Excellence, then, is \\ not an act, but a habit." \\ -Will Durant, The Story of Philosophy: \\ The Lives and Opinions of the World's \\ Greatest Philosophers
}

This year's recipient of the American Association for Thoracic Surgery's Scientific Achievement Award is Eugene H. Blackstone, MD. Dr Blackstone has been a prolific cardiothoracic surgery investigator whose dedication, intelligence, and knowledge of statistics, computer programming, and cardiothoracic surgery have allowed him to not only make important contributions to science but also advance the specialty of cardiothoracic surgery.

\section{BACKGROUND AND EDUCATION}

As a boy, Eugene enjoyed music. There was a strong tradition of musicians in his family. His grandfather played string bass in the Toronto symphony, and both his parents were violinists. At a young age, he learned to play the marimba, then the piano, and then the pipe organ, a hobby he continues to enjoy today. As with everything he does, he dedicated himself to the study of music and practiced no less than 4 hours a day.

Despite his love of music, Eugene embarked on a career in medicine. His fondness for the University of Chicago (where his father spent many summers in the basement of the Oriental Institute, reviewing archeological treasures) led him to apply only there for college. He was accepted, and his cardiothoracic surgery research began under the tutelage of Hassan Najafi in the field of transplantation.

As one would expect, Eugene was an excellent student. He was given the opportunity to pursue a Rhodes scholarship or to accept early admission to medical school. He choose the latter, and matriculated into the University of Chicago Medical School. Throughout his years there, he worked in the laboratory of Dr Peter Moulder, investigating myocardial protection, a pulsator device for external left ventricular assistance, the effects of hypothermic nonpulsatile perfusion, acid-base balance, and the processing of

From Cleveland Clinic, Cleveland, Ohio.

Disclosures: Author has nothing to disclose with regard to commercial support.

Address for reprints: Joseph F. Sabik III, MD, 9500 Euclid Ave, Mail Code J4-1,

Cleveland, OH 44195 (E-mail: sabikj@ccf.org).

J Thorac Cardiovasc Surg 2013;146:1003-5

$0022-5223 / \$ 36.00$

Copyright (c) 2013 by The American Association for Thoracic Surgery

http://dx.doi.org/10.1016/j.jtcvs.2013.09.001

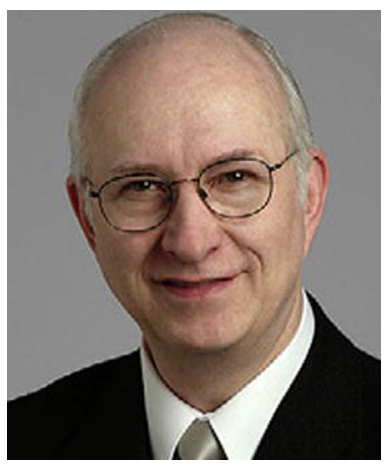

hemodynamic signals in hopes of inventing a way to measure pulmonary arterial resistance noninvasively.

During his third-year medical school preceptor conference, he was advised to consider a career as a full-time clinical investigator. The Public Health Service and National Library of Medicine were promoting such careers, with a strong emphasis on "computers in medicine." Eugene liked this idea, and during his senior year chose electives in mathematics, statistics, and computer science. He received his medical degree with honors and stayed at the University of Chicago as a postdoctoral fellow. For 3 years, he was the Douglas Smith Fellow and E.F. Andrews Fellow. During this time, he also worked in the Biological Computation Center at the Billings Hospital as part of an interdisciplinary team of statisticians, mathematicians, biophysicists, operations researchers, and signal processing experts, headed by Dr Paul Meier, then chairman of Statistics. This group was the first to use Fast Fourier Transform in medicine, and they developed a new field that was ultimately called "digital signal processing."

During this time of education and research, he also reflected on marriage. As completely unromantic as it sounds, but completely in line with Dr Blackstone's nature, he took a systematic approach to choosing a wife. He compiled criteria on the pros and cons of marriage and applied them to women he had liked from grade school through medical school. He decided on Janet Hawkins, the daughter of a classmate of his parents, who also enjoyed music. They corresponded for 3 years before deciding to meet for a first date. In 1968, they were married.

After marriage, Dr Blackstone decided it was time to move on with his career and pursue surgical training. In the 1960s, one of the few quantitative medical research specialties was cardiac surgery. On the advice of Dr Moulder, Dr Blackstone submitted a paper on his work to the American Association for Thoracic Surgery and met with Dr John Kirklin, the one person he thought would appreciate 
someone with quantitative knowledge. Dr Kirklin invited Dr Blackstone to become a surgical intern at the University of Alabama in Birmingham. This was the beginning of one of the most important partnerships in cardiothoracic surgery.

At that time the Vietnam War was raging, but the draft board had held off on inducting him until he was a licensed physician. After completing his internship, Dr Blackstone was offered a laboratory position in a US Army Medical Department research laboratory if he would agree to stay 3 years. He chose Fort Rucker, home of the Aeromedical Research Laboratory, the closest laboratory to the University of Alabama in Birmingham. Here, he continued his work on developing digital signal processing.

\section{ACADEMIC POSITIONS}

\section{University of Alabama}

In 1972, after completing his military service, Dr Blackstone was again recruited by Dr Kirklin, this time to serve in the University of Alabama's Department of Surgery as a full-time physician-investigator. He rapidly progressed from Assistant Professor to an Endowed Full Professor by 1980 , a position he held until 1997. Dr Blackstone and Dr Kirklin worked together closely and by the 1980s began sharing an office in order to collaborate more effectively. This partnership led to one of the most important and prolific cardiothoracic research programs of the time. Their activities included studying circulatory arrest, myocardial protection, the molecular basis for the damaging effects of cardiopulmonary bypass, development of miniature devices for cardiopulmonary support, mathematical simulation of congenital heart diseases and their treatment, and simulation of process control for managing unstable patients after heart surgery. In addition, Dr Blackstone and Dr Kirklin assisted in development of the Northern New England Cardiovascular Disease Study Group, New York State Cardiac Surgery Reporting System, Congenital Heart Surgeons Society Data Center, and the first American College of Cardiology/American Heart Association guidelines for coronary artery bypass surgery that were data driven, rather than based on expert opinion.

In addition to his collaboration with Dr Kirklin in cardiothoracic surgery, Dr Blackstone worked with his university colleagues in mathematics and statistics, devising novel models for time-related outcomes, writing computer programs for analysis of both time-related signals and timerelated events, and conducting randomized clinical trials and studies of clinical experiences. The saga of the Braunwald-Cutter valve, and its subsequent "recall" requiring reoperation, brought into stark relief the inadequacies of analytic tools for time-related events. In 1983, he and his colleagues devised a statistical method of temporal decomposition of time-related events that solved this problem. This ushered in an era of concentrating on long-term outcomes of cardiac surgery, with an emphasis on appropriateness of care.

An educational endowment brought as many as a dozen research fellows each year into this collaborative environment at the University of Alabama. These academic activities culminated in the first 2 editions of the textbook Cardiac Surgery, on which Dr Blackstone collaborated extensively, and more than 200 original scientific publications. In 1987, Dr Kirklin became editor of The Journal of Thoracic and Cardiovascular Surgery and Dr Blackstone became the associate editor. Dr Blackstone has served as an associate editor for the subsequent 3 editors-Drs Waldhausen, Wechsler, and Cohn.

\section{Cleveland Clinic}

By the mid-1990s, Dr Blackstone had decided to find a new venue for the second half of his career. He made strategic trips to a number of centers, including one to Cleveland Clinic. He had resisted $\mathrm{Dr}$ Toby Cosgrove's invitations to visit the Clinic for 5 years-knowing it would be a recruiting trip. After finally accepting Dr Cosgrove's offer, Dr Blackstone realized that the position at the Clinic would offer him new-and different-opportunities. The job would be in adult, not congenital, heart disease. It would not have a laboratory component; however, a wealth of clinical data was available for analysis.

In 1997, Dr Blackstone joined the Cleveland Clinic as Head of Clinical Research in the Department of Thoracic and Cardiovascular Surgery. Under his leadership, this group became the largest and most prolific cardiothoracic surgery clinical research program in the world. Dr Blackstone's multidisciplinary team focused on ischemic and valvular heart diseases, heart rhythm disturbances, heart failure (including transplantation, ventricular assist devices, and alternatives to transplantation), and development of new statistical and database methods.

Presently, Dr Blackstone is Head of Clinical Investigations and holds the Kenneth Gee and Paula Shaw, $\mathrm{PhD}$, Chair in Heart Research in the Heart and Vascular Institute at Cleveland Clinic. During his tenure, one of Dr Blackstone's main focuses has been on mentoring surgeons, physicians, medical students, statisticians, and computer programmers in statistics and cardiothoracic surgery research. His efforts have advanced the careers of many young physicians, surgeons, and scientists.

While in Cleveland, Dr Blackstone has also led in writing and editing the third and fourth editions of Cardiac Surgery, authored or co-authored more than 350 peer-reviewed papers, and received National Institutes of Health funding for developing novel statistical techniques (machine learning) and semantic representation and processing of complex biological data. In 1998, he again 
became an associate editor of The Journal of Thoracic and Cardiovascular Surgery, from 1998 to 2008 served on the Scientific Advisory Board of The Journal of Heart Valve Disease, and from 2005 to the present has been an editorial consultant for the Journal of the American College of Cardiology.

\section{AWARDS AND ACADEMIC ACTIVITIES}

Dr Blackstone has received numerous awards for his academic achievements and contributions to the fields of cardiothoracic surgery and statistical analysis. During his time at the University of Chicago Medical School, he received the Mosby Scholarship Award and Merck Scholastic Achievement Award in 1966, and the Chicago Surgical Society Annual Award for Surgical Research for development and experimental studies of a cardiac assist device in 1968. For his work in time and frequency domain computer analysis of periodic biological information and noise rejection in such signals, he received the U.S. Army Meritorious Service Medal in 1972. The University of Chicago honored him with the Alumni Association
Distinguished Service Award, Division of Biological Sciences, in 1998, and during his tenure at the Cleveland Clinic he has received the Maria and Sam Miller Professional Excellence Award for Scientific Achievement in Clinical Research in 2003 and was awarded the Kenneth Gee and Paula Shaw, PhD, Chair in Heart Research in 2007. Dr Blackstone is a member of numerous academic societies spanning the fields of medicine, statistics, and computer programming.

\section{SUMMARY}

Dr Blackstone is a unique scientific researcher and one of the most prolific and important cardiothoracic scientists of our time. Through his understanding of cardiothoracic surgery, computer programming, and statistical analysis, he has advanced cardiothoracic surgery research to a level that would not have been attainable without a person of his knowledge, skill, and dedication. His lifelong work has had a profound effect not only on our understanding of cardiothoracic surgical treatment but also on improving the care of patients with cardiothoracic disease. 